\title{
Bireysel Zaman Baskısının Satın Alma Sonrası Pişmanlığa Etkisinde Alışverişte Zaman Baskısının Aracı Rolü Üzerine Bir Araştırma
}

\author{
DOI: $10.26466 /$ opus.518712 \\ * \\ İbrahim Bozaci ${ }^{*}$ \\ * Dr. Öğr. Üyesi , Kırıkkale Üniversitesi, Keskin Meslek Yüksekokulu, Pazarlama ve Reklamcılık \\ Bölümü, Keskin/ Kırıkkale / Türkiye \\ E-Posta: $\underline{\text { iborganizer@gmail.com }}$ \\ ORCID: 0000-0002-9584-6126
}

\begin{abstract}
Öz
Bu çalışmanın amacı, zaman baskısının satın alma sonrası pişmanlık üzerindeki etkisini, zaman baskısı türlerine (bireysel zaman baskısı, alışverişte zaman baskısı) göre belirlemektir. Zaman baskısı pazarlama literatüründe tüketiciye etkileri bakımından araştırılan önemli konulardan biridir. Ancak araştırmalarda, konunun daha çok alışverişte yaşanan zaman baskısı düzeyinde ele alındığı ve bireysel zaman baskısının göz ardı edildiği görülmektedir. Yerli pazarlama yazınında ise konuyla ilgili gerçekleştirilen araştırma sayısı azdır. Çalışmada öncelikle zaman baskısı ve alışverişte zaman baskısıyla ilgili bilimsel araştırmalar incelenmektedir. Ardından bireysel zaman baskısının tüketicinin satın alma sonrası pişmanlığa etkisinde alışverişte zaman baskısının aracılık rolü üzerine Kırıkkale ilinde bir anket çalışması gerçekleştirilmektedir. Elde edilen veriler istatistiksel paket programıyla analiz edilmektedir. Araştırma neticesinde bireysel zaman baskısının alışverişte zaman baskısını ve satın alma sonrası pişmanlığı önemli düzeyde açıkladı̆̆ı ve alışverişte zaman baskısının bireysel zaman baskısının satın alma sonrası pişmanliğa olan etkisinde tam aracılık rolü üstlendiği tespit edilmektedir. Bunlarm yanında demografik özelliklere bağh olarak bireysel ve alışverişte zaman baskısındaki farklllıklar incelenmektedir. Son olarak işletme ve araştırmacılara öneriler geliştirilmektedir.
\end{abstract}

Anahtar Kelimeler: Zaman Baskısı, Alışverişte Zaman Baskısı, Satın Alma Sonrası Pişmanlık 


\title{
A Research on The Mediating Role of Time Pressure in Shopping at The Effect of Individual Time Pressure on Post-Purchase Regret
}

\begin{abstract}
The goal of this study is to determine the effect of time pressure on post-purchase regret accordingto the types of time pressure (individual time pressure and time pressure at shopping). Time pressure is one of the important topics investigated in terms of consumer effects in marketing literature. However, in studies, it is seen that the issue is mostly dealt with at the level of time pressure experienced at shoping and that individual time pressure is ignored. The subject has not received enough attention in domestic marketing literature. In this study, scientific researches related to time pressure and time pressure in purchasing is examined primarily. Then, a questionnaire study is carried out in the province of Kirlkkale on the mediating role of time pressure in shopping in the effect of individual time pressure on consumer's regret after purchasing. The obtained data were analyzed with statistical package program. As a result ot the research, it was determined that the individual time pressure explains the time pressure in shopping and post purchase regret at a significant level, and that the time pressure of shopping has the full mediating role in the effect of the individual time pressure on post-purchase regret. In addition to these, the differences in individual time pressure and time pressure in shopping with respect to demographic variables are examined. Lastly, suggestions for businesses and researches have been developed.
\end{abstract}

Keywords: Individual Time Pressure, Time Pressure in Shopping, Post-Purchase Regret 


\section{Giriş}

Zaman kavramı, tüketici davranışlarında yeterince incelenmemesine karşın tüketiciler kararlarını önemli oranda zamana bağlı olarak vermektedir. Örneğin ihtiyacın ve ürünün farkına varma, ürün ve işletmelerle ilgili bilgi kaynaklarını araştırmaya başlama, araştırma, araştırmayı bitirme, mesajlara maruz kalmaya başlama (reklam, ambalaj vb.), mesajlara maruz kalmayı bitirme, satın almaya karar verme, alışverişe başlama, alışverişi bitirme, ürünü kullanma için hazırlanmaya başlama, kullanma için hazırlanmayı bitirme, kullanmaya başlama ve kullanmayı bitirme gibi tüketici davranışlarının tamamı zaman bağlı/zamana bağımlı kararlardır (Jacoby vd., 1976).

Zaman ile iç içe olan tüketici davranışlarının, tüketicinin sahip olduğu zamanla ilgili algılamalardan etkilenmemesi düşünülemez. Tüketicilerin zamanının kısıtlı olması, zaman baskısının ölçülmesinin zorluğu, zaman baskısının kişiden kişiye değişen bir durum olması ve insanların geçmişe göre daha fazla zaman baskısı altında yaşamak zorunda kalması (eşlerin çalışması vb.) gibi faktörler son zamanlarda pazarlama alanında konuya olan ilgiyi artırmaktadır. Bu çalışmada, tüketicinin hayatında yaşadığı bireysel zaman baskısı, alışverişte zaman baskısı ve satın alma sonrası pişmanlık arasındaki ilişkiler incelenerek özellikle yerli pazarlama literatüründeki boşluğun giderilmesine katkı sağlamak ve bireysel zaman algısının tüketiciye etkilerini belirli değişkenler bakımından aydınlatmak amaçlanmaktadır. Bu kapsamda öncelikle pazarlama alanında zaman ve zaman baskısıyla ilgili araştırmalar incelenerek araştırma değişkenleri belirlenmekte ve Kırıkkale ilinde bir alan araştırmasıyla zaman baskısının tüketicilere olası etkileri incelenmektedir.

\section{Zaman Baskısı, Zaman Baskısının Değişkenliği ve Etkileri}

Zaman baskısı, belirli bir görevi yerine getirme (bilgi işleme, satın alma kararı verme vb.) için gereken zamanın (veya zaman kaynağının) kısıtlı olarak algılanması veya buna ilişkin bir psikolojik gerilim halidir (Smith ve Hayne, 1997; Rajneesh ve Monroe, 2003; Fisher vd., 2003).

Algılamalara dayalı göreceli bir kavram olan zaman baskısı, kişiye ve durumsal özelliklere göre değişmektedir. Bireyin belirli anda yaşadığı 
duygu (huşu ile negatif ilişkili) (Rudd vd., 2012, s.1130) ve demografik özellikler zaman baskısını etkileyebilmektedir. Saigal ve Mann (2010)'un çalışmasına göre; erkek, genç, evli, eğitim düzeyi yüksek ve kendi işinin sahibi insanlar daha fazla zaman baskısı yaşayabilmektedir. Dolayısıyla zaman baskının ve etkilerinin analizinde demografik özelliklerin önemli değişkenler olabileceği anlaşılmaktadır.

Zaman baskısının bireye etkileriyle ilgili araştırmalar; bilgiyi daha az işleme tabi tutma ve daha az bilgiye dayalı karar verme (Vlasic vd., 2011: 87), yanliş/istenmeyen kararlar verme (Young vd., 2012), daha fazla stres yaşama (Kleiner, 2014), uyku sorunları yaşama, hasta olduğunda doktora görünmeyi erteleme (Zhong ve DeVoe, 2010), daha az boş zaman faaliyetlerinde bulunma ve akıl sağlığının kötüleşmesi (Zuzanek, 1998) gibi sonuçları olduğunu göstermektedir. Bireyin doğru karar alma becerilerini azaltan, zihinsel ve duygusal yapısı üzerinde olumsuz etkileri olan zaman baskısının, tüketici davranışları bakımından da özellikle bilgiye dayalı karar almama, yanlış satın alma tercihlerinde bulunma ve dolayısıyla daha fazla satın alma sonrası pişmanlık yaşama durumunu etkilemesini beklemek mümkündür.

\section{Alışverişlerde Zaman Baskısı}

Tüketici davranışı; güdülenme, satın alma ve satın almanın sonuçlarını değerlendirme gibi aşamaları içeren bir süreç olduğundan, tüketicinin zamanla ilgili bilişsel yapısı; güdülerini, planlarını, tükettikleri ürünleri ve tutumlarını etkiler. Tüketiciler, zaman baskısı hissettiklerinde, daha iyi karar vermek ve çözüm üretmek için yeterince zamanı olmadıklarını düşünmektedir (Ahituv vd., 1998).

Uygulamada işletmeler, zaman baskısı yaşayan tüketicilerin ihtiyaçlarını karşılama bakımından bu durumdan yararlanabilmektedir. Tüketiciye zaman kazandıran ürünlerin geliştirilmesi ve pazarlanması mümkündür (Darian ve Cohen, 1995). Örneğin ütülenme gerektirmeyen giysi, dondurulmuş gıda, otomatik makine (yıkama, kurulama vb.), evlere servis yiyecek hizmeti ve havayolu hizmeti pazarlamacıları müşteriler için zaman faydası oluşturmakta ve zaman baskısı yüksek olan müşterileri öncelikli olarak hedefleyebilmektedir. 
Bunların yanında işletmeler, ürünleri kısa sürede satın almasını özendirerek oluşturduğu zaman baskısını pazarlama yöntemi olarak kullanabilmektedir. Satış geliştirme faaliyetleri genel olarak tüketicinin kısa sürede ürünleri satın almasını sağlamak üzere tasarlanmaktadır (Spears, 2001). Ayrıca fuar gibi organizasyonların kısa süre için düzenlenmesi (2 veya 3 gün) ile tüketicide oluşan zaman baskısı, karar almak için endişeye, satın alma baskısına, kıtlık, fiyat ve kalite algilamalarının etkilenmesine neden olmaktadır (Lim, 2013). İşletmeler tarafından oluşturulan zaman baskısının diğer bir örneği açık artırmalardır. Adam ve diğerleri (2015)'in çalışmasına göre zaman baskısına bağlı olarak ve diğer teklifçiler olduğunda, teklifçiler uyarılmakta ve daha yüksek teklifler vermektedir (Adam vd., 2015).

Tüketicide işletmeler tarafından oluşturulan zaman baskısının; olumsuz bilgiye odaklanma (Wright, 1974; Zur ve Breznitz, 1981), marka farkındalığının yüksek olduğu ürünlere dikkati verme (Liu vd., 2017), görsel bilgiden önce yazılı bilgiyi değerlendirme (Pieters vd., 1997; Pieters ve Warlop, 1999; Rieskamp ve Hoffrage, 2008) ile ilişkili olduğunu göstermektedir. Ancak bu araştırmalarda, genellikle işletme uygulamalarından kaynaklı tüketicinin yaşadığı zaman baskısı incelemekte olup (Mitomi, 2017, s.280), işletmeler özellikle bu doğrultuda çaba göstermeden de tüketiciler alışverişlerinde zaman baskısı yaşayabilmektedir. Özellikle bireysel düzeyde zaman baskısını yüksek düzeyde yaşayanların, alışverişlerinde de zaman baskısını daha fazla hissetmesi mümkündür.

Tüketicilerin alışverişlerinde algıladığı zaman baskısının artması; daha az araştırma ve değerlendirme çabasında bulunma (Vlasic vd, 2011; Lin ve $\mathrm{Wu}, 2005)$, daha hizlı karar verme (Dhar ve Nowlis, 1999), daha sezgisel (Pieters ve Warlop, 1999), gelişigüzel, plansız veya içtepkisel karar verme (Inbar vd., 2011: 533; Park vd., 1989; Do Prado vd., 2016; Sohn ve Lee, 2017), daha fazla olumsuz duygular yaşama (Sohn ve Lee, 2017; Gross, 1994), satın alma eğiliminin azalması, mobil reklam ve markaya yönelik tutumların kötüleşmesi (Rau vd., 2014), online alışverişlere yönelik daha olumlu tutumlara sahip olma (Xu-Priour vd., 2012), ve daha fazla satın alma sonrası tercihlerle ilgili pişmanlık yaşama (Inbar vd., 2011) gibi durumlarla ilişkilidir.

Türkiye'de zaman baskısı ve tüketim konusuyla ilgili gerçekleştirilen az sayıda araştırma vardır. Bunlardan, Güleç ve Quadir (2015)'in 
alışverişteki zaman baskısını bir tür alışveriş alışkanlığı olarak değerlendirdikleri çalışması; tüketicilerin yaklaşık \% 30'unun alışverişte zaman baskısı hissettiğini ve erkeklerin ve yaşça küçük olanların alışverişlerde daha fazla zaman baskısı yaşadığını göstermektedir. Özmen (2006) ise alışverişlerle ilgili algılanan zamanın, tüketicinin memnuniyetini etkileyebileceğini ve işletmelerin tüketicilerin alışverişlerde geçirdiği zamanı boşa harcadığını düşünmesini engellemesi gerektiğini teorik düzeyde ileri sürmektedir. İplik'in (2005) saha araştırmasına göre, alışverişte algılanan zaman baskısı, alışveriş sürecinden memnuniyetle ters yönlü ilişkilidir.

Yerli ve yabancı pazarlama literatüründeki konuyla ilgili çalışmalarda, tüketicinin bireysel veya hayatında genel olarak hissettiği zaman baskısının değerlendirilmemesi ve bireysel zaman baskısı ile alışverişte zaman baskısı arasındaki farklılığın incelenmemesi, bireysel zaman baskısının alışverişte zaman baskısıyla ilişkisinin ve bireysel zaman baskısının tüketiciye etkisinde alışverişte zaman baskısının rolünün incelenmemesi söz konusudur. Ancak bireysel zaman baskısını daha fazla hissedenlerin, bu özelliklerinin alışverişlerine de yansıması mümkündür.

Zaman baskısını bireysel düzeyde ele alan ve tüketicilere etkilerini inceleyen araştırma sayısının, alışverişte zaman baskısını inceleyenlere göre az olduğu görülmektedir. Zaman baskısını bu düzeyde ele alan Saigal ve Mann'ın (2010) çalışması, bireysel düzeyde hayatında daha fazla zaman baskısı hissetmenin, alışverişlerde daha az bilgi araştırma davranışıyla ilişkili olduğunu göstermektedir. Kongarchapatara ve Shannon (2016) ise bireysel düzeyde zaman baskısı veya stresi yüksek olanların, alışverişte daha az zaman ve enerji harcamak için belirli mağazaya daha fazla sadakat gösterdiği sonucuna ulaşmıştır. Belirtilen bu çalışmaların sonuçları, bireysel zaman baskısının tüketicinin satın almalarda yeterince bilgi araştırmasını, karşılaştırma yapmasını, doğru tercihlerde bulunmasını olumsuz etkileyebileceği ve satın alma sonrası daha fazla pişmanlık yaşayacağı fikrini desteklemektedir.

Alışverişte yaşanan zaman baskısının temel sonuçlarından birinin, yanlış tercihlere bağlı olarak satın alma sonrası veya tercih pişmanlığı olduğunu Inbar vd.'nin (2011) çalışması göstermektedir. Ancak bu noktada, bireysel zaman baskısının alışverişte zaman baskısına ve dolayısıyla satın alma sonrası pişmanlığa etkisinin birlikte incelenmediği görülmektedir. Bu çalışmada bireysel zaman baskısının satın alma sonrası 
pişmanlığa etkisinde, alışverişte zaman baskısının rolü bir saha araştırmasiyla incelenmektedir.

Tüketicide oluşan pişmanlık duygusuyla ilgili gerçekleştirilen bilimsel çalışmalar son zamanlarda artmaktadır (Mannetti vd., 2007). Tüketiciler alışverişlerinden elde ettikleri faydayı artırmak veya pişmanlıklarını en aza indirmek için farklı düzeylerde de olsa çaba göstermektedir (Chorus vd., 2013). Konuyla ilgili gerçekleştirilen araştırmalar müşterinin satın alma sonrası müşteri pişmanlığının; satın alma öncesi yeterince bilişsel çaba göstermeme, bilgi araştırmama veya karşılaştırma yapmama (Park vd., 2015, Liang vd., 2018), satın alma öncesi alternatiflerin farkında olmama (Lin ve Huang, 2006), riskten korunma amaçlı planlı satın almalarda bulunma (Spears, 2006), risk tutumları ve satın alma deneyimleri (Chen ve Jia, 2012), satın alma sonrasında da gerçekleştirilen karşılaştırma davranışı (Cooke vd., 2001), yoksun kalınan ürün alternatiflerin olması ve bunların farkına varılması (Tsiros ve Mittal, 2000, Tsiros, 2009) gibi değişkenlerle ilişkili olduğunu göstermektedir. Bu çalışmada, müşterinin satın alma öncesinde bilgi araştırma, karşılaştırma, alternatiflerin farkına varma ve plan yapma gibi zaman ve çaba gerektiren davranışları olumsuz etkileyen bir durum olarak zaman baskısının (bireysel ve alışverişte), müşteride satın alma sonrası pişmanlığa neden olduğu ileri sürülmekte, bu kapsamda araştırma modeli oluşturulmakta ve model birincil verilerle test edilmektedir.

\section{Bireysel Zaman Baskısının, Satın Alma Sonrası Pişmanlığa Etkisinde Alışverişte Zaman Baskısının Aracı Rolü Üzerine Bir Araştırma}

Araştırmanın uygulama aşamasında, bireysel düzeyde yaşanan zaman baskısının, alışverişlerde yaşanan zaman baskısı ile ilişkisi ve bunların satın alma sonrası pişmanlıkla ilişkileri incelenmektedir. Özellikle alı̧̧verişte yaşanan zaman baskısının, bireysel zaman baskısının satın alma sonrası pişmanlığa etkisinde aracı rolü olup olmadığı test edilmektedir. 


\section{Araştırmanın Amacı, Önemi, Modeli ve Yöntemi}

Araştırmanın amacı, tüketicinin hayatındaki yaşadığı bireysel zaman baskısının satın alma sonrası pişmanlığa etkisinde, alışverişte yaşanan zaman baskısının aracılık rolünü aydınlatmaktır. Bu noktada çalışma, alışverişlerde yaşanan zaman baskısı ile birlikte, tüketicinin genel olarak hayatında yaşadığı zaman baskısını birlikte değerlendirmesi bakımından önem arz etmektedir. Zira hayatlarında zaman baskısı yüksek olan tüketicilerin, alışverişlerde daha az zaman baskısı yaşadığında satın alma sonrası pişmanlık durumdaki değişimlerin bilinmesi, işletmelerin tüketiciler için doğru kararlar almasına katkı sağlayacaktır. Araştırma kapsamında oluşturulan model Şekil 1.'de görüldü̈̆ü gibidir:

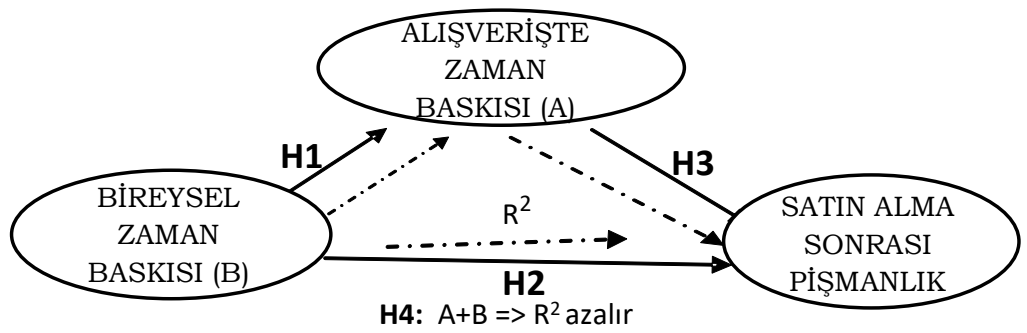

Şekil 1. Araştırma Modeli

Araştırma kapsamında oluşturulan hipotezler aşağıdaki gibidir:

H1: Bireysel zaman baskısı, alışverişte zaman baskısını etkilemektedir.

H2: Bireysel zaman baskısı, satın alma sonrası pişmanlığı etkilemektedir.

H3: Alışverişte zaman baskısı, satın alma sonrası pişmanlığı etkilemektedir.

H4: Bireysel zaman baskısının satın alma sonrası pişmanlığa etkisinde, alışverişte zaman baskısı aracı rol üstlenmektedir.

Araştırma amaçlarına ulaşma doğrultusunda, araştırma soru formunu geliştirmek üzere konuyla ilgili bilimsel çalışmalardaki ölçüm araçlarından yararlanılmıştır. İfadeler araştırmaya katılanların katılma düzeyinin yer aldığ ${ }_{1}$ 'li Likert tarzında tasarlanmıştır. Bireysel zaman algısını ölçmek için (Saigal ve Mann, 2010; Rudd vd., 2012; Etkin vd., 2015; Kon- 
garchapatara ve Shannon, 2016; Srinivasan ve Ratchford, 1991) çalışmalarındaki ifadelerden yararlanılmıştır. Alışverişlerde hissedilen zaman baskısını belirlemek için (Weenig ve Maarleveld, 2002; Inbar vd., 2011; Lim, 2013) araştırmalarındaki ifadeler çalışmaya uyarlanmıştır. Son olarak, satın alma sonrası pişmanlığ tespit etmek için (Inbar vd., 2011) çalışmasındaki ifadelerden yararlanılmıştır. Bunların yanında katılımcıların demografik özelliklerine ilişkin sorulara araştırma soru formunda yer verilmiştir.

Tablo 1. Katılımcıların Demografik Özellikleri

\begin{tabular}{|c|c|c|c|c|}
\hline Cinsiyet & Miktar & Yüzde & Geçerli Yüzde & Birikimli Yüzde \\
\hline Erkek & 170 & 42,4 & 44,0 & 44,0 \\
\hline Kadın & 216 & 53,9 & 56,0 & 100,0 \\
\hline Yanitlamayanlar & 15 & 3,7 & & \\
\hline Toplam & 401 & 100,0 & & \\
\hline \multicolumn{5}{|l|}{ Gelir } \\
\hline 900 TL ve altı & 85 & 21,2 & 21,4 & 21,4 \\
\hline 901- 2000 TL & 116 & 28,9 & 29,2 & 50,6 \\
\hline 2001-3500 TL & 152 & 37,9 & 38,3 & 88,9 \\
\hline $3501-5000 \mathrm{TL}$ & 30 & 7,5 & 7,6 & 96,5 \\
\hline 5001 TL ve üstü & 14 & 3,5 & 3,5 & 100,0 \\
\hline Yanitlamayanlar & 4 & 1,0 & & \\
\hline Toplam & 401 & 100,0 & & \\
\hline \multicolumn{5}{|l|}{ Eğitim } \\
\hline İlkokul ve altı & 40 & 10,0 & 10,1 & 10,1 \\
\hline Ortaokul & 65 & 16,2 & 16,4 & 26,4 \\
\hline Lise & 189 & 47,1 & 47,6 & 74,1 \\
\hline Ön lisans & 55 & 13,7 & 13,9 & 87,9 \\
\hline Lisans ve üstü & 48 & 12,0 & 12,1 & 100,0 \\
\hline Yanitlamayanlar & 4 & 1,0 & & \\
\hline Toplam & 401 & 100,0 & & \\
\hline \multicolumn{5}{|l|}{ Yaş } \\
\hline 21 ve altı & 41 & 10,2 & 10,4 & 10,4 \\
\hline $22-27$ & 78 & 19,5 & 19,7 & 30,1 \\
\hline $28-33$ & 97 & 24,2 & 24,5 & 54,5 \\
\hline $34-39$ & 79 & 19,7 & 19,9 & 74,5 \\
\hline 40 ve üstü & 101 & 25,2 & 25,5 & 100,0 \\
\hline Yanitlamayanlar & 5 & 1,2 & & \\
\hline Toplam & 401 & 100,0 & & \\
\hline
\end{tabular}

Araştırma kapsamında, kaynak kısıtlarından dolayı Kırıkkale ilinde kolayda örnekleme ile seçilen 401 kişi ile anket çalışması gerçekleştirilmiştir. Katılımcıların cinsiyetle ilgili soruya yanıt verenlerin \% 44'ü erkek, \% 56'sı kadındır. Gelir bakımından ise katılımcıların \% 
$88,9^{\prime}$ u 3.500 TL ve altı gelir grubunda yer almaktadır. Eğitim düzeyi bakımından katılımcıların \% 47,6'sı lise, \% 16,4'ü ortaokul mezunudur. Yaş bakımından ise katılımcların \% 24,5'i 28-33, \% 19,9'u 34-39 ve \% 19,7'si 22-27 yaş aralığındadır.

\section{Güvenirlik ve Faktör Analizleri}

Araştırma soru formu ve değişkenlerine yönelik gerçekleştirilen güvenirlik analizine göre, Cronbach Alfa katsayısı, genel soru formu için 0,965 olarak hesaplanmıştır.

Tablo 2. Faktör Analizi

\begin{tabular}{|c|c|c|c|c|}
\hline & $\begin{array}{l}\text { Faktör } \\
\text { Yükü }\end{array}$ & $\begin{array}{l}\text { Öz } \\
\text { değer }\end{array}$ & $\begin{array}{l}\text { Açıklanan } \\
\text { Varyans }\end{array}$ & $\begin{array}{l}\text { Toplam } \\
\text { Varyans }\end{array}$ \\
\hline 1. Faktör: Bireysel Zaman Baskısı & & 4,515 & 34,729 & 34,729 \\
\hline Zaman hızla akıp gidiyor & 816 & & & \\
\hline Tanıdığım kişilere göre daha meşgul görünürüm & 802 & & & \\
\hline Kendimi genelde zaman baskısı altında hissederim & ,794 & & & \\
\hline Yapmak istediğim şeyler için asla yeterince zamanım olmaz & ,777 & & & \\
\hline Yapacağım bir çok şey için keşke daha fazla zamanım olsaydı & ,770 & & & \\
\hline Çok fazla boş zamanım olmaz & ,765 & & & \\
\hline 2. Faktör: Alışverişte Zaman Baskısı & & 3,848 & 29,603 & 64,332 \\
\hline Alışverişimi gerçekleştirirken aciliyet hissederim & ,833 & & & \\
\hline Alışveriş yaparken, satın almayı hızlandırma gereği hissederim &, 830 & & & \\
\hline $\begin{array}{l}\text { Alışveriş kararı alırken bir an önce bitmesi gerektiğini } \\
\text { hissederim }\end{array}$ &, 822 & & & \\
\hline $\begin{array}{l}\text { Alışverişlerimde karar almak için yeterince zamanım olma- } \\
\text { dığını hissederim }\end{array}$ & ,816 & & & \\
\hline Alışveriş yaparken uzun uzun düşünmekten hoşlanmam &, 809 & & & \\
\hline 3. Faktör: Satın Alma Sonrası Pişmanlık & & 1,732 & 13,327 & 77,659 \\
\hline Alışverişlerimdeki tercihlerimden pişman olurum & ,868 & & & \\
\hline $\begin{array}{l}\text { Daha fazla zamanım olsaydı, daha doğru alışveriş kararları } \\
\text { alırdım }\end{array}$ &, 856 & & & \\
\hline
\end{tabular}

Bireysel zaman baskısı değişkenini belirlemek üzere oluşturulan altı ifadenin güvenirlik katsayısı, 0,934; alışverişte zaman baskısını belirlemek için oluşturulan soruların güvenirlik katsayısı 0,925; ve son olarak satın alma 
sonrası pişmanlık değişkenini ölçmek için hazırlanan iki sorunun güvenirlik katsayısının 0,783 olduğu tespit edilmiştir. Dolayısıyla genel olarak anket sorularının ve değişkenleri belirleyen soru gruplarının iç tutarlılığının yüksek olduğu anlaşılmaktadır.

Araştırma kapsamında oluşturulan ifadelere yönelik açıklayıcı faktör analizi gerçekleştirilmiştir. Analiz sonuçlarına göre veri setinin faktör analizine uygunluğunu gösteren KMO katsayısı 0,912 ve anlamlı olarak tespit edilmiştir. Buna göre araştırmada kullanılan maddeler toplam varyansın \% 77,7'sini açılayan üç faktör altında toplanmıştır. Faktörlerin açıkladığı varyanslar, özdeğerler ve maddelerin faktörlere dağılımını içeren faktör analizi sonuçları Tablo 2.'deki gibidir:

\section{Farklılıkların İncelenmesi}

Araştırmanın bu kısmında, araştırma değişkenlerinin katılımcıların temel özelliklerine göre farklılaşma durumu incelenmektedir. İki grup arasındaki farklılıklar test etmek üzere bağımsız örneklem t-testi, ikiden fazla grup arasındaki farklılıkları tespit etmek üzere Anova testi gerçekleştirilmiştir. Cinsiyete göre farklılıklar incelendiğinde; bireysel zaman baskısının ve alışverişte zaman baskısının erkeklerde kadınlara göre daha yüksek olduğu tespit edilmiştir.

Farklılık analizi sonuçlarına göre gelir, eğitim ve yaş gruplarına göre de anlamlı farklılıklar görülmektedir. Gelire göre farklılıklar incelendiğinde, zaman baskısı ve alışverişte zaman baskısının en fazla en yüksek gelir grubundaki bireylerde olduğu, en düşük ise 900 TL ve altı gelir grubundaki bireylerde olduğu görülmektedir. Eğitim düzeyine göre farklılıklar incelendiğinde; bireysel zaman baskısının en yüksek, lisans ve üstü, en düşük ilkokul ve altı eğitim düzeyindekilerde olduğu tespit edilmiştir. Alışverişte zaman baskısının ise en yüksek önlisans ve lisans ve üstü eğitim düzeyine sahip olanlarda olduğu, en düşük ise ilkokul ve altı eğitim düzeyine sahip olanlarda olduğu görülmektedir. Yaş gruplarında göre araştırma değişkenlerinin farklılıkları incelendiğinde, bireysel ve alışverişte zaman baskısının en fazla 21 ve altı, en az 40 ve üstü yaş grubundakilerde olduğu tespit edilmiştir. 40 yaş üstündekilerin zaman baskısının ve satın alma sonrası pişmanlığının görece düşük olması, alışveriş davranışları ve zaman yönetimi bakımından tecrübeli olmaları 
ile ilişkili olduğu düşünülmektedir. Bu sonuçlar, erkek, genç ve eğitim durumu yüksek olanlarda alışverişte zaman baskısının yüksek olduğunu gösteren Saigal ve Mann'ın (2010) ve erkek ve gençlerde alışverişte zaman baskısının daha yüksek olduğunu gösteren Güleç ve Quadir'in (2015) çalışma sonuçlarına benzerlik göstermektedir.

Tablo 3. Demografik Özelliklere Göre Farklılıklar

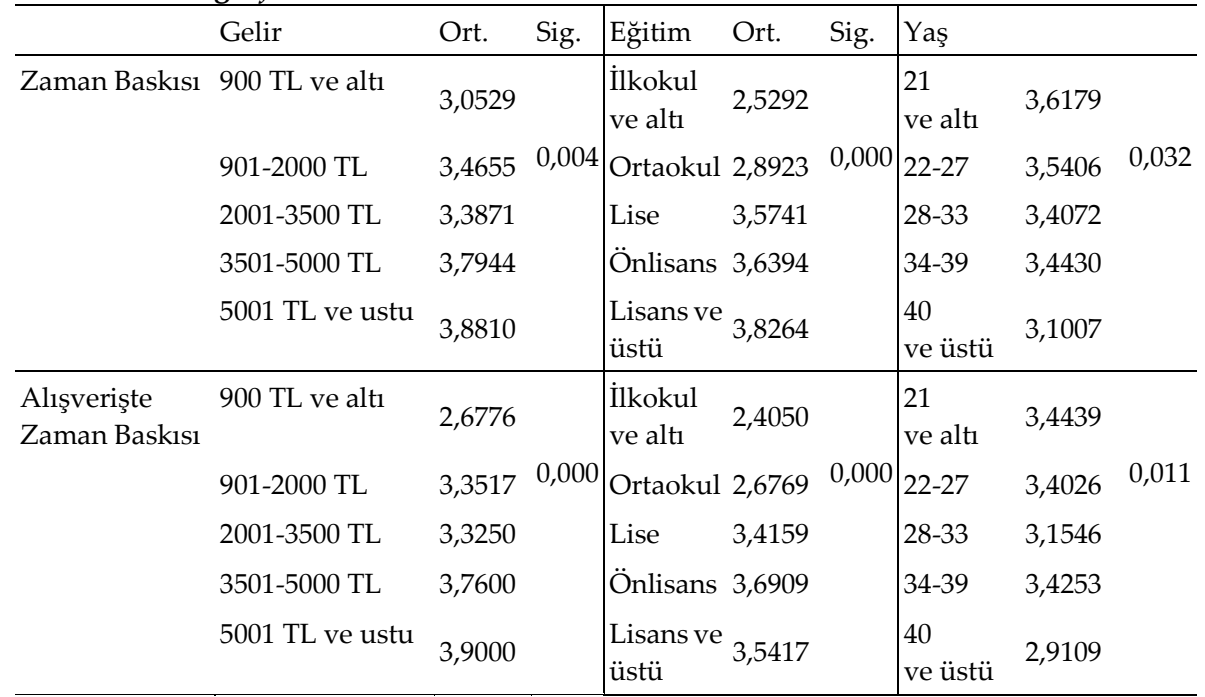

\begin{tabular}{llll}
\hline Cinsiyet & & & \\
\hline Zaman Baskısı & Kadın & 3,2000 & 0,014 \\
& Erkek & 3,4776 & \\
Alışverişte & Kadın & 2,8647 & \multirow{2}{*}{0,000} \\
Zaman Baskısı & Erkek & 3,4657 & \\
\hline
\end{tabular}

\section{İlişki Analizi}

Değişkenler arası ilişkileri analiz etmek için gerçekleştirilen korelasyon analizi sonuçlarına göre; bireysel zaman baskısının, alışverişte zaman baskısı ile anlamlı ve orta düzeyde ilişkili olduğu tespit edilmiştir. Dolayısıyla genel olarak hayatında zaman baskısı hissedenlerin, alışverişlerde de daha fazla zaman baskısı hissetmesi söz konusudur. Ayrıca bireysel zaman baskısı ile satın alma sonrası pişmanlık arasında 
anlamlı ve düşük düzeyde ilişki tespit edilmiştir. Dolayısıyla bireysel zaman baskısının alışverişlerde doğru karar almayla ilişkili bir faktör olabileceği fikri desteklenmektedir.

Bunların yanında alışverişte zaman baskısının satın alma sonrası pişmanlık ile olumlu şekilde ve bireysel zaman baskısına göre daha fazla ilişkili olduğu tespit edilmektedir. Bu sonuç da, alışverişte yaşanan zaman baskısının doğru alışveriş kararları vermede bireysel zaman baskısına göre daha yüksek düzeyde ilişkili bir değişken olduğu şeklinde yorumlanmaktadır.

Tablo 4. Korelasyon Analizi

\begin{tabular}{llc}
\hline & Alışverişte Zaman Baskısı & Satın Alma Sonrası Pişmanlık \\
\hline Zaman Baskısı &, $661^{* *}$ &, $316^{* *}$ \\
&, 000 &, 000 \\
\hline Alışverişte Zaman Baskısı & 1 &, $381^{* *}$ \\
& &, 000 \\
\hline
\end{tabular}

\section{Regresyon Analizi}

Araştırma hipotezlerini test etmek üzere regresyon analizi gerçekleştirilmiştir. Bir değişkenin aracılık rolünü üstlenmesi için bağımsız değişkenin aracı değişkeni ve bağımlı değişkeni etkilemesi, bağımsız ve aracı değişken birlikte bağımlı değişkeni etkilerken bağımsız değişkenin etkisinin azalması veya kaybolması koşulları gerçekleşmelidir (Baron ve Kenny, 1986). Gerçekleştirilen analizler sonucunda bağımsız değişken olan bireysel zaman baskısının aracı değişken olan alışverişte zaman baskısını etkilediği tespit edilmiştir (R2: 0,477). Dolayısıyla H1 desteklenmektedir. Ayrıca, bağımsız değişken olan bireysel zaman baskısının bağımlı değişken olan satın alma sonrası pişmanlığı da etkilediği görülmüştür (R2: 0,171). Dolayısıyla H2 hipotezi desteklenmektedir. Bunların yanında, bireysel zaman baskısı ve alışverişte zaman baskısının birlikte değerlendirildiğinde, alışverişte zaman baskısının satın alma sonrası pişmanlığı etkilediği $(\beta: 0,432)$ görülmekte ve H3 hipotezi desteklenmektedir. 
Aynı koşulda bireysel zaman baskısının satın alma sonrası pişmanlık üzerindeki etkisinin anlamsızlaştığ $1(\beta: 0,108)$ tespit edilmekte ve H4 hipotezi desteklenmektedir. Bireysel zaman baskısının, alışverişte zaman baskısı değişkeni olduğunda etkisinin istatistiksel olarak anlamsız düzeyde olması, bu değişkenin tam aracılık rolü üstlendiğini göstermektedir.

$\mathrm{Bu}$ sonuçlar alışverişte zaman baskısının, tüketicinin tercih pişmanlığını etkilediğini gösteren Innbar vd.'nin (2011) çalışma sonuçlarıyla örtüşmektedir. Bunun yanında, alışverişte zaman baskısının, bireysel zaman baskısının tüketicinin satın alma sonrası pişmanlığa etkisinde aracılık rolüne yönelik elde edilen bulgu, araştırmanın özgün sonucudur. Tablo 5.'de regresyon analizi sonuçları görülmektedir:

Tablo 5. Regresyon Analizi

\begin{tabular}{|c|c|c|c|}
\hline \multicolumn{4}{|c|}{ I. Model. Bireysel Zaman Baskısının Alışverişte Zaman Baskısını Açıklayıcılığı } \\
\hline & Beta Katsayısı & $\mathrm{t}$ & sig. \\
\hline Zaman baskisı & 629 & 14,578 & , 000 \\
\hline Cinsiyet & 270 & 2,780 & ,006 \\
\hline Gelir & ,075 & 1,184 & ,237 \\
\hline Eğitim & ,040 & ,795 & ,427 \\
\hline Meslek &,- 086 & $-2,431$ & ,016 \\
\hline Yaş &,- 029 &,- 769 & ,442 \\
\hline $\mathrm{F}$ & 55,709 & \multicolumn{2}{|c|}{ Sig. 0,000} \\
\hline $\mathrm{R}=0,691$ & $\mathrm{R}^{2}=0,477$ & & \\
\hline \multicolumn{4}{|c|}{ II. Model. Bireysel Zaman Baskısının Satın Alma Sonrası Pişmanlığı Açıklayıcılığı } \\
\hline Zaman baskisı & ,372 & 6,341 & ,000 \\
\hline Cinsiyet &,- 324 & $-2,447$ & ,015 \\
\hline Gelir & -158 & $-1,836$ & ,067 \\
\hline Eğitim & ,002 & ,034 & 973 \\
\hline Meslek &,- 119 & $-2,441$ & ,015 \\
\hline Yaş &,- 081 & $-1,567$ & 118 \\
\hline $\mathrm{F}$ & 11,951 & \multicolumn{2}{|c|}{ Sig. 0,000} \\
\hline$R=0,413$ & $R^{2}=0,171$ & & \\
\hline \multicolumn{4}{|c|}{$\begin{array}{l}\text { III. Model. Bireysel Zaman baskısı ve Alışverişte Zaman Baskısının Satın Alma Sonrası Pişmanlı̆̆ } \\
\text { Açıklayıclığı }\end{array}$} \\
\hline Alışverişte zaman baskısı & 432 & ,066 & 000 \\
\hline Zaman baskısı & 108 & ,069 & 116 \\
\hline Cinsiyet &,- 445 & 127 & ,000 \\
\hline Gelir &,- 189 & 082 & ,021 \\
\hline Eğitim &,- 021 & 065 & 749 \\
\hline Meslek &,- 083 & ,046 & ,075 \\
\hline Yaş &,- 064 & ,049 & 190 \\
\hline $\mathrm{F}$ & 17,500 & \multirow{2}{*}{\multicolumn{2}{|c|}{ Sig. 0,000}} \\
\hline $\mathrm{R}=0,511$ & $\mathrm{R}^{2}=0,261$ & & \\
\hline
\end{tabular}




\section{Sonuç}

Tüketicinin yaşadığı bireysel zaman baskısı, alışverişte zaman baskısı ve satın alma sonrası pişmanlık arasındaki ilişkilerin incelendiği bu çalışmada; alışverişte zaman baskısının, bireysel zaman baskısının satın alma sonrası pişmanlığa etkisine aracılık ettiği fikrini desteklenmektedir. Bu sonuç, bireysel zaman baskısı yüksek olanların, her ne kadar alışverişte zaman baskısı yaşama olasılıkları yüksek olsa da, alışverişte zaman baskısı hissetmediklerinde veya düşürülmesi sağlandığında, satın alma sonrası pişmanlık düzeylerinin azalabileceğini göstermektedir.

Araştırma verilerinin analizi neticesinde, bireysel zaman baskısının satın alma sonrası pişmanlığın \% 17'sini açıkladığı, bu değişkenin alışverişte zaman baskısı ile birlikte satın alma sonrası pişmanlığı \% 26 'sını açıkladığı tespit edilmiştir. Ayrıca bireysel zaman baskısının satın alma sonrası pişmanlık üzerindeki etkisi, alışverişte zaman baskısı değişkeniyle birlikte olduğunda ortadan kalkmaktadır. Bunların yanında, bireysel zaman baskısının, alışverişte zaman baskısının \% 48'ini açıkladığ 1 tespit edilmektedir. Dolayısıyla bireysel zaman baskısının, satın alma sonrası pişmanlığı; alışverişte zaman baskısı üzerinden etkilediği sonucuna varılmaktadır.

Araştırma sonuçlarının işletmeler için yararlı olduğu düşünülmektedir. İşletmelerin, her ne kadar bireysel zaman baskısı yüksek olsa da, tüketicilerin alışverişlerde yaşadığı zaman baskısını engellediklerinde, satın alma sonrası pişmanlık duygularını azaltması mümkündür. Zira işletmelerin bireysel zaman baskısını etkilemesi zor olsa da, alışveriş ortamında zamanla ilgili algılamaları ve zaman baskısını etkilemesi mümkündür. Örneğin araştırmalar müzik, 1şıklandırma, eğlendirici araçlar ve bilgilendirici anonslarının müşterilerin mağaza ortamındaki zamanla ilgili algılamalarını etkilediğini göstermektedir (Pruyn ve Smidts, 1998; Gail vd., 1997; Kellaris ve Altsech, 1992; Kellaris ve Kent, 1992). Bu gibi mağaza atmosferi araçlarının tüketiciler üzerindeki etkilerini, alışverişte zaman baskısını etkileyen önemli bir değişken olarak bireysel zaman baskısını da göz önünde bulundurarak değerlendirmek, hangi araçların etkin olarak kullanılabileceğinin daha bütüncül olarak değerlendirilmesine katkı sağlayacaktır. 
Araştırmada özellikle erkeklerin, geliri yüksek olanların ve eğitim düzeyi yüksek olanların daha fazla bireysel ve alışverişte zaman baskısı yaşadığ1 tespit edilmiştir. Dolayısıyla bu özelliklere sahip müşterileri öncelikle hedefleyen, bu özelliklerdeki müşterilerin daha yoğun olduğu bölge veya zamanlarda işletmelerin, bireysel ve alışverişte zaman baskısı ve sonuçlarına önem vermesinin faydalı olacağı düşünülmektedir.

Araştırma sonuçlarının tüm tüketicilere yönelik genelleştirilememesi, araştırmada betimsel nitelikte anket yönteminin kullanılması ve araştırmaya katılanların dürüst yanıtlar verdiğinin varsayılması araştırmanın başlıca kısıtlarını oluşturmaktadır. Ancak çalışma sonuçlarının, tüketiciyi etkileyen önemli bir olguyu ve etkilerini incelemesi, konuyu özgün bir bakış açısıyla tartışmaya açması, araştırmada ileri sürülen hipotezlere belirli bölge için kanıt sunması ve işletmeler için yararlı bilgiler üretmesi bakımından yararlı olduğu düşünülmektedir. 


\title{
EXTENDED ABSTRACT
}

\section{A Research on The Mediating Role of Time Pressure in Shopping at The Effect of Individual Time Pressure on Post-Purchase Regret}

\author{
İbrahim Bozac1 \\ Kırıkkale University
}

It is unthinkable that consumer behaviors, that are intertwined with time, are not affected by the time perceptions of consumers. Factors such as the limited time of consumers, the difficulty of measuring time pressure, the fact that time pressure differs from person to person, and people have to live under more time pressure than past, have recently increased the interest toward the subject of time pressure in marketing. This study is conducted to determine the effect of time pressure on post-purchase regret of consumers. In marketing literature it is seen that time pressure can be general at individual level or specific at purchasing level. At this point, marketing researches generally take into consideration the phenomenon from one point of view, either individual time pressure or shopping time pressure. In most studies, the issue is mostly dealt with at the level of shopping based time pressure and individual time pressure is ignored. Since present study evaluates both of the time pressure types simultaneously in consumption context, it is thought that the viewpoint is original. Moreover, it is seen that although subject of the time pressure is researched in many studies in foreign marketing literature, there is few studies in domestic literature. So this study is hoped to contribute to fill the gap in this research area.

The aim of the study is to illuminate the mediating role of shopping time pressure at the effect of individual time pressure on consumer postpurchase regret. Because, when consumers with high time pressure in their lives and experiences more time pressure at purchasings, knowing the changes in post-purchase regret will help enterprises make right decisions for consumers. 
In this study, scientific researches related to time pressure and time pressure in purchasing is examined first. After that a questionnaire study is carried out in the province of Kırıkkale to scrutinize the mediating role of time pressure in shopping at the effect of individual time pressure on consumer's regret after purchasing. To design research questionnaire and measure the research variables, the measurement tools and items developed in the previous studies related with the subject are benefited by adapting to study. The data was gathered from 401 people with convenience sampling method. The obtained data were analyzed with statistical package program. Cronbach Alpha coefficiens are calculated for reliability analysis and the results shows high internal consistency of the research variables and general questionaire. Factor analysis points out the structural validity of the survey and its dimensions. Moreover, descriptive analysis, correlation analysis, difference analysis (t-tests and anova tests) and regression analysis were made at the study.

As a result ot the statistical analyses, it was determined that male, younger and more educated consumers have more time pressure for both time pressure types. In addition, individual time pressure explains \% 17 of he post-purchase regret and the shopping time pressure explains \% 26 of the post-purchase regret. Furthermore, the effect of individual time pressure on post-purchase regrets disappears when shopping time pressure added to model. In addition to these, it is depicted that individual time pressure explains $\% 48$ of the shopping time pressure. So, it is understood that individual time pressure affect post-purchase regret through the shopping time pressure.

Research results would be useful for firms. Because even though the individual time pressure is high, it is possible for businesses to reduce their feelings of post-purchase regret when they prevent the shopping time pressure. Although it is difficult for firms to affect individual time pressure, it is possible to affect the perceptions and time pressure on time in the shopping environment. For example, research shows that music, lighting, entertaining tools, and informative announcements affet the perceptions of customers in store (Pruyn and Smidts, 1998; Gail et al., 1997; Kellaris and Altsech, 1992; Kellaris and Kent, 1992). Evaluating the effects of such atmosphere tools on consumers, taking into account individual 
time pressure as an important variable affecting time pressure in shopping, will contribute to a more holistic evaluation of which tools can be used effectively.

The main constraints of the study are that the results of the research can not be generalized to all consumers, the use of the descriptive survey method and the assumption that the participants give honest and true answers. However, it is thought that the results of the study are important in terms of examining an important phenomenon and its effects that affect consumer behavior, opening the subject to discussion with a unique point of view, providing evidence for the specified hypotheses in the research and providing useful information for businesses and researches.

\section{Kaynakça / References}

Adam, M. T., Krämer, J. ve Müller, M. B. (2015). Auction fever! How time pressure and social competition affect bidders' arousal and bids in retail auctions. Journal of Retailing, 91(3), 468-485.

Ahituv, N., Igbaria, M. ve Sella, A. V. (1998). The effects of time pressure and completeness of information on decision making. Journal of Management Information, 15(2), 154-172.

Baron, R. M. ve Kenny, D.K. (1986). The moderator-mediator variable distinction in social psychological research: Conceptual, strategic, and statistical considerations. Journal of Personality and Social Psychology, 51(6), 1173-1182.

Chen, R., ve Jia, J. (2012). Regret and performance uncertainty in consumer repeat choice. Marketing Letters, 23(1), 353-365.

Chorus, C. G., Koetse, M. J., ve Hoen, A. (2013). Consumer preferences for alternative fuel vehicles: Comparing a utility maximization and a regret minimization model. Energy Policy, 61, 901-908.

Cooke, A. D., Meyvis, T., ve Schwartz, A. (2001). Avoiding future regret in purchase-timing decisions. Journal of Consumer Research, 27(4), 447-459.

Darian, J. C. ve Cohen, J. (1995). Segmenting by Consumer Time Shortage. Journal of Consumer Marketing, 12(1), 32-44.

Dhar, R. ve Nowlis, S.M. (1999). The effect of time pressure on consumer choice deferral. Journal of Consumer Research, 25(4), 369-384. 
Do Prado, R. Pereira, A.D. ve Lopes, E.L. (2016). Tick Tock, Tick Tock! An experimental study on the time pressure effect on omission neglect. Journal of International Consumer Marketing, 28(5), 332-346.

Etkin, J., Evangelidis, I. ve Aaker, J. (2015). Pressed for time? Goal conflict shapes how time is perceived, spent, and valued. Journal of Marketing Research, 52(3), 394-406.

Fisher, C. W., Chengalur-Smith, I. ve Ballou, D.P. (2003). The impact of experience and time on the use of data quality information in decision making. Information Systems Research, 14(2), 170-188.

Gail, T., Bums, M. ve Zeng, Y. (1997). Your life on hold. The effect of telephone waiting time on customer perception. Journal of Direct Marketing, 11(3), 25-31.

Gross, B.L. (1994). Consumer responses to time pressure: A qualitative study with homeowners in foreclosure. Advances in Consumer Research, 21, 120-125.

Güleç, İ.H. ve Quadir, S.E. (2015, Ekim). Hedonik tüketim bağımlılı̆̆ kapsamında kamu çalışanlarının rekreasyonel alışveriş eğilimlerinin incelenmesi. 1. Uluslar arası Uygulamalı Bilimler Kongresi, Konya, 876-889.

Inbar, Y., Botti, S. ve Hanko, K. (2011). Decision speed and choice regret: When haste feels like waste. Journal of Experimental Social Psychology, 47(3), 533-540.

İplik, E. (2005). Kalabalık ve zaman baskısı altındaki tüketicilerin alışverişten duyduklar tatmin düzeyini belirlemeye yönelik bir çalışma. Yayımlanmamış Yüksek Lisans Tezi, Çukurova Üniversitesi, Sosyal Bilimler Enstitüsü İşletme Anabilim Dalı, Adana.

Jacoby, J., Szybillo, G.J., ve Berning, C.K. (1976). Time and consumer behavior: An interdisciplinary overview. Journal of Consumer Research, 2(4), 320-339.

Kellaris, J. J. ve Kent, R. (1992). the influence of music on consumers' temporal perceptions: Does time fly when you're having fun?. Journal of Consumer Psychology, 1(4), 365-376.

Kellaris, J. J., ve Altsech, M. B. (1992). The experience of time as a function of musical loudness and gender of listener. Advances in Consumer Research, 19, 725-729. 
Kleiner, S. (2014). Subjective time pressure: General or domain specific?. Social Science Research, 47, 108-120.

Kongarchapatara, B. ve Shannon, R. (2016). The effect of time stress on store loyalty: A case of food and grocery shopping in Thailand. Australasian Marketing Journal (AMJ), 24(4), 267-274.

Liang, X., Liu, P., ve Liu, Z. (2018). Selecting products considering the regret behavior of consumer: A decision support model based on online ratings. Symmetry, 10(5), 178.

Lim, C. (2013). Analysis of time pressure and value perception: An exploratory study of consumer travel fair. Journal of Travel ve Tourism Marketing, 30(5), 509-521.

Lin, C. H., ve Huang, W. H. (2006). The influence of unawareness set and order effects in consumer regret. Journal of Business and Psychology, 21(2), 293-311.

Lin, C.H. ve Wu, P.H. (2005). How to deal with conflicts? The effect of consumers subjective time pressure on product attitude judgment and choice. Journal of American Academy of Business, 6, 219-224.

Liu, C.W., Hsieh, A.Y., Lo, S.K., ve Hwang, Y. (2017). What consumers see when time is running out: Consumers' browsing behaviors on online shopping websites when under time pressure. Computers in Human Behavior, 70, 391-397.

Mannetti, L., Pierro, A., ve Kruglanski, A. (2007). Who regrets more after choosing a non-status-quo option? Post decisional regret under need for cognitive closure. Journal of Economic Psychology, 28(2), 186-196.

Mitomi, Y. (2017). What is marketing time pressure?. Annals of Business Administrative Science, 16(6), 275-285.

Özmen, M. (2006). Perakendecilikte tüketicinin zaman algılaması ve zaman algılamasının müşteri tatmini üzerine etkisi: Kavramsal bir bakış. Afyon Kocatepe Üniversitesi İ.I.B.F. Dergisi, VIII(2), 225-236.

Park, C. W., Easwar S. I., ve Smith, D. C. (1989). The effects of situational factors on in-store grocery shopping behavior: The role of store environment and time available for shopping. Journal of Consumer Research, 15(4), 422-433. 
Park, J., Hill, W. T., ve Bonds-Raacke, J. (2015). Exploring the relationship between cognitive effort exertion and regret in online vs. offline shopping. Computers in Human Behavior, 49, 444-450.

Pieters, R. ve Warlop, L. (1999). Visual attention during brand choice: The impact of time pressure and task motivation. International Journal of Research in Marketing, 16(1), 1-16.

Pieters, R., Warlop, L. ve Hartog, M. (1997). The effect of time pressure and task motivation on visual attention to brands. Advances in Consumer Research, 24, 281-287.

Pruyn, A. ve Smidts, A. (1998). Effects of waiting on the satisfaction with the service: Beyond objective time measures. Internatioml Jouml of Research in Murketing, 15(4), 321-334.

Rajneesh, S. ve Monroe, K.B. (2003). the effects of time constraints on consumers'judgments of prices and products. Journal of Consumer Research, 30(1), 92-104.

Rau, PL.P., Zhou, J. Chen, D. ve Lu, T.P. (2014). The influence of repetition and time pressure on effectiveness of mobile advertising messages. Telematics and Informatics, 31(3), 463-476.

Rieskamp, J. ve Hoffrage, U. (2008). Inferences under time pressure: How opportunity costs affect strategy selection. Acta Psychologica,127, 258-276.

Rudd, M.,Vohs, K.ve Aaker, J. (2012). Awe expands people's perception of time, alters decision making, and enhances well-being. Psychological Science, 23(10), 1130-36.

Saigal, B. ve Mann, B.J.S. (2010). The mediating role of demographics and time pressure in information search process: A comparative analysis of english and Indian consumers. IUP Journal of Marketing Management, 9(1/2), 7-22.

Smith, C. A. P., ve Hayne, S.C. (1997). Decision making under time pressure: an investigation of decision speed and decision quality of computer-supported groups. Management Communication Quarterly, 11(1), 97-126.

Sohn, H.K. ve Lee, T. (2017). Tourists' impulse buying behavior at dutyfree shops: The moderating effects of time pressure and shopping involvement. Journal of Travel ve Tourism Marketing, 34(3), 341-356. 
Spears, N. (2001). Time pressure and information in sales promotion strategy: Conceptual framework and content analysis. Journal of Advertising, 30(1), 67-76.

Spears, N. (2006). Just moseying around and happening upon it versus a master plan: Minimizing regret in impulse versus planned sales promotion purchases. Psychology ve Marketing, 23(1), 57-73.

Srinivasan, N. ve Ratchford, B.T. (1991). An empirical test of a model of external search for automobiles. Journal of Consumer Research, 18(2), 233-242.

Tsiros, M. (2008). Releasing the regret lock: Consumer response to new alternatives after a sale. Journal of Consumer Research, 35(6), 10391059.

Tsiros, M., ve Mittal, V. (2000). Regret: A model of its antecedents and consequences in consumer decision making. Journal of Consumer Research, 26(4), 401-417.

Vlašić, G., Janković, M. ve Čaluk, A.K. (2011). Information hunt: The impact of product type and time pressure on choice of information source for purchase decisions. Management: Journal of Contemporary Management Issues, 16(2), 87-103.

Weenig, M. W.H. ve Maarleveld, M. (2002). The impact of time constraint on information search strategies in complex choice tasks. Journal of Economic Psychology, 23, 689-702.

Wright, P. (1974). The harassed decision maker: Time pressures, distractions, and the use of evidence. Journal of Applied Psychology, 59, 555561.

Xu-Priour, D.L., Cliquet, G. ve Fu, G. (2012). The combined influence of time pressure and time orientation on consumers' multichannel choice: Evidence from China. The International Review of Retail, Distribution and Consumer Research, 22(5), 529-546.

Young, D. L., Goodie, A.S., Hall, D. B. ve Wu, E. (2012). Decision making under time pressure, modeled in a prospect theory framework. Organizational Behavior ve Human Decision Processes, 118(2), 79-188.

Zhong, C.B. ve Devoe, S. E. (2010). You are how you eat: Fast food and impatience. Psychological Science, 21, 619-623.

Zur, H.B. ve Breznitz, S.J. (1981). The Effect of time pressure on risky choice behavior. Acta Psychologica, 47(1), 89-104. 
Zuzanek, J. (1998). Time use, time pressure, personal stress, mental health, and life satisfaction from a life cycle perspective. Journal of Occupational Science, 5(1), 26-39.

\section{Kaynakça Bilgisi / Citation Information}

Bozacı, İ. (2019). Bireysel zaman baskısının satın alma sonrası pişmanlığa etkisinde alışverişte zaman baskısının aracı rolü üzerine bir araştırma. OPUS-Uluslararası Toplum Araştırmaları Dergisi, 10(17), 653676. DOI: $10.26466 /$ opus. 518712 